\title{
Integración, Desintegración e Intensificación en los Cuentos de Juan Rulfo
}

$\mathrm{E}$ I Llano en llamas de Juan Rulfo nos of rece una variedad de temas y técnicas. No obstante, podemos hallar algunas constantes que rigen el proceso creativo de sus cuentos. Nuestro propósito será el de examinar cuáles son esas constantes y cuál su función literaria. Creemos haber discernido tres: los procesos de integración, desintegración e intensificación. El último es tal vez el más importante por influir sobre los otros dos; de manera que una separación total sería arbitraria, y sólo se hace aquí como medio válido para nuestra exposición.

\section{INTEGRACIÓN}

El efecto principal de la integración en Juan Rulfo es el de crear un mundo establemente grotesco.

Dentro de este mundo las cosas forman un medioambiente dinámico, vívido y fluido, en el que se establece una comunión entre las fuerzas de la naturaleza y las del hombre. Esta comunión existe no sólo en el plano psicológico, sino también en el de la acción. Examinemos, por ejemplo, el pasaje siguiente:

La luna grande de octubre pegaba de lleno sobre el corral y mandaba hasta la pared de mi casa la sombra larga de Remigio...

Pero al quitarse él de enfrente, la luz de la luna hizo brillar la aguja de arria que yo había clavado en el costal. $Y$ no sé por qué, pero de pronto comencé a tener una fe muy grande en aquella aguja...1

I Juan Rulfo, "La cuesta de las Comadres", en El llano en llamas (México, Fondo de Cultura Económica, 1953), pp. 28-29. Todas las citas son por esta edición. 
La luna aquí desarrolla la doble función de indicar al personaje la presencia del otro y a la vez mostrarle la herramienta con la cual va a matarle. En la última frase del pasaje citado, el personaje siente lo que él llama una "fe" en la aguja, que no existió antes de que la luna la "hizo brillar". Es una fe que surgió "de pronto" y que puede ser atribuida exclusivamente a la acción de la luna. La luz crea una seried de circunstancias en las cuales la reacción del personaje está ya predeterminada.

Estilísticamente, la integración de las fuerzas de la naturaleza con las humanas para determinar una sola acción se logra mediante una técnica que consiste en reforzar el vocabulario. Las palabras adquieren nueva fuerza por su interrelación. Por ejemplo, en el pasaje siguiente:

Soltó el machete que llevaba todavía apretado en la mano cuando el frío le entumeció las manos. Lo dejó allí. Lo vio brillar como un pedazo de culebra sin vida, entre las espigas secas.

Va y viene como una serpentina enroscada sobre la tierra verde. . .2

La palabra "culebra" forma una comparación con el machete, mientras que "serpentina" se refiere al río. La primera relación es a base de una herramienta, producto muy común de la acción humana; la segunda, a base de una manifestación igualmente común de la naturaleza. "Machete" y "culebra" establecen una relación única entre las dos fuerzas: integran la naturaleza y lo humano. Así se logra, no sólo una integración entre elementos estilísticos aislados, sino también entre tema, personaje y ambiente. Esta integración es producto de un estilo en el cual el personaje actúa de acuerdo con sus circunstancias, que son determinadas por las cosas que lo rodean y de acuerdo con el tema central.

Analicemos estos tres elementos: personaje, circunstancias y tema.

Hemos dicho que el personaje actúa de acuerdo con sus circunstancias. Esto le quita cualquier posibilidad de libre albedrio. Sus reacciones son predeterminadas. El desarrollo de la trama vital crece sistemáticamente; tan sistemáticamente que produce cierta tensión. El lector anticipa lo que va a suceder, pero esto no disminuye su interés; al contrario, lo intensifica. Los hechos pasan uno tras otro, llevándonos a una conclusión inevitable. $Y$ de esta misma inevitabilidad nace la tensión del lector para ver cómo el "fin irremediable" se hace un "fait accompli"'.

2 Ibid, "El hombre", p. 39. 
O sea que Rulfo ha creado un papel nuevo para el lector, una nueva función de éste en la estructura del cuento. El lector ahora encuentra que su interés ha sido transferido de la cuestión, tan presente en el cuento usual de ¿cómo va a terminarse la acción?, a una participación activa en el hecho de verlo suceder.

Las circunstancias son determinadas por las cosas que forman la realidad concreta. Pero lo importante es que cada elemento de la naturaleza tiene su propia fuerza, que el creador debe descubrir y poner en acción. Fs la combinación de estas fuerzas, más que de las cosas entre sí, lo que crea la serie de circunstancias. O sea que mientras las cosas existen por sí mismas, es la fuerza o actuación que el autor les otorga lo que constituye el mundo del personaje.

El tema domina la creación tanto del personaje como del ambiente. No hay descripción que no sirva para desarrollar mejor el punto central. El efecto de esta integración es la creación de una tensión tanto psicológica como literaria. Produce un mundo en que las acciones y reacciones son inevitables. El desarrollo ocurre de tal o cual modo porque no puede ocurrir de otro, pues este mundo de lo establemente grotesco no admite otras posibilidades.

A primera vista, este proceso podría parecer debilitante por crear este tipo de inevitabilidad. Seria lógico esperar que la narración sufriera. En realidad, tenemos todo lo contrario; pues los cuentos de Juan Rulfo no son cuentos sólo de personajes, sino cuentos que ejemplifican la condición humana y su composición. Es cierto que las fuerzas externas adquieren una importancia tal vez desproporcionada. Pero esto no constituye ninguna falla técnica en el autor. Es más bien la expresión de toda una doctrina literario-filosófica de la relación entre el individuo y el mundo que le rodea. Es imposible entender el valor de estos cuentos' sin reconocer esta base filosófica y su influjo sobre la "estilística" y perspectiva técnica de la obra.

\section{DESINTEGRACIóN}

En la obra de Juan Rulfo aparecen tres tipos fundamentales de desintegración. El primero se relaciona con las circunstancias que se bifurcan para formar dos mundos totalmente separados, cuyo único punto de contacto es el mismo personaje. Estos dos mundos, que podríamos denominar como el mundo del "es" y el mundo del "tal vez sea", nunca se enfrentan en la realidad. Son aceptados desde el principio como 
dos entidades distintas que ni pueden ni deben acercarse. Ambos mundos existen en la percepción del personaje, pero éste es su único plano de coexistencia. El mismo personaje sabe distinguir entre ellos, pero sin perder de vista la seguridad de que ambos tienen influencia sobre su condición y su perspectiva.

En el plano psicológico esta desintegración lleva a una especulación de parte del personaje sobre el carácter de lo real. En lugar de una afirmación decisiva de la realidad existente, lleva a un proceso mental especulativo sobre varias posibilidades. Estas posibilidades, aunque caben dentro de la realidad (i.e., nunca participan de la fantasía pura), no son limitadas por ésta. Pueden alejarse de la realidad concreta para entrar en el reino de la realidad posible.

$A$ veces esta realidad posible reemplaza a la realidad concreta o la aumenta. En tales casos, el mundo de la posibilidad es el que influye sobre las acciones humanas, sobre todo cuando la realidad concreta es indefinida o desconocida. Tenemos, por ejemplo, el pasaje siguiente:

$Y$ aquí ha de haber sucedido eso de que se durmió. Tal vez se le ocurrió despertar al sentir que el agua pesada le golpeaba las costillas. Tal vez entonces se asustó y trató de regresar; pero al volverse se encontró entreverada y acalambrada entre aquella agua negra y dura como tierra corrediza. Tal vez bramó pidiendo que le ayudaran. ${ }^{3}$

Aquí se conoce cierta parte de la realidad concreta. Una vaca se ahogó en la corriente. Pero esa parte de la realidad del suceso no basta para determinar la reacción del personaje. Así que el autor le permite entrar en el plano del "tal vez" para completar el ambiente, tanto psicológico como físico, necesario para su desarrollo. Pero lo importante es notar que en ninguna ocasión Rulfo deja que esta realidad determinada se confunda con aquella otra. Son dos elementos que a veces ejercen una influencia simultáneamente, pero no dependen el uno del otro, ni se relacionan más que en lo relativo y necesario para el desarrollo completo de la perspectiva individual del personaje.

El medioambiente que el autor nos presenta es en sí una manifestación de esa desintegración. Es un mundo en el cual los sistemas y valores conocidos no figuran. Es un mundo de violencia, poblado de niños retardados, mujeres de mala fama $y$ hombres insatisfechos con su condición, pero a la vez impotentes, incapaces de efectuar un cambio

3 Ibid, "Es que somos muy pobres", p. 33. 
positivo en su estado. Es un mundo que podría explicarse si fuera de post-guerra, si existiera alguna razón terrible pero concreta que lo hubiera producido. Pero no se nos ofrece razón alguna para la existencia de este mundo; existe porque sí y nada más. Es un mundo que está allí para desintegrarse por su propia cuenta. Es un mundo a la vez determinado y determinante por su propia existencia. Aunque se está desintegrando, mantiene la fuerza suficiente como para resistir cualquier cambio. Si tal cosa puede existir, es una desintegración estable; un mundo que siempre está desintegrándose, pero que nunca se desintegra por completo.

La combinación de esta desintegración del medioambiente y la incapacidad de los personajes suele producir un cambio - siempre pesimista- en la perspectiva de éstos. Por ejemplo, en el cuento citado la muerte de la vaca cambia toda la perspectiva de uno de los personajes. La vaca era la dote de su hija, sin la cual puede perderse en la "mala vida", o, por lo menos, ésta es la interpretación que el padre da al hecho.

Así vemos que las cosas más mínimas en el esquema de la realidad, tal como la conocemos los lectores, adquieren gran importancia en el mundo rulfiano. El hombre se halla sujeto a los errores y accif dentes de la naturaleza. En todo momento está existiendo como víctima del azar; de tal suerte que la desintegración gradual y constante de su. ámbito circunstancial lo lleva a una desintegración paralela de su mundo íntimo, individual o personal.

Tal vez el caso de mayor interés en el proceso de desintegración es! el fenómeno de la separación del personaje de su propia presencia. Esto en ninguna forma implica que se nos dé personajes puramente psicoló-! gicos. Al contrario, las figuras protagónicas en la obra de Rulfo son muy "de carne y hueso". Lo que sí ocurre es un alejamiento de ciertos modos de la existencia física del personaje. Pero a la vez, este mismo alejamiento se percibe por medio de los sentidos. Técnica difícil de precisar, no obstante su mucha aplicación. Como ejemplo, ofrecemos el caso siguiente:

Oía su voz, su propia voz, saliendo despacio de su boca. La sentía sonar como una cosa falsa y sin sentido.

Para el personaje, su voz, su "propia" voz, algo íntimo de lo cual él se creía dominador, ya no le pertenece. Actúa por sí misma, saliendo casi por su propia cuenta de su boca. Y está saliendo "despacio" para que

4 Ibid, "El hombre", p. 41. 
toda palabra y todo intento de las palabras se perciba y se entienda. Le parece "como una cosa falsa", pues la asociación normal entre la voz y la persona ha sido destruida.

De este modo vemos que hasta los sentidos físicos del personaje se convierten en cosa extraña a él; o sea, en fuerza externa e independiente. Lo físico todavía se percibe por lo físico; y no sólo por lo físico abstracto, sino por el sentido que lo correspondiera en la realidad. Pero parte de la existencia física ha sido quitada. Es su voz, y él la percibe y la siente y sabe que es suya. Sin embargo, ha sido extendida, ampliada; ha llegado a un plano nuevo en el cual el personaje se siente extranjero, exilado de uno de los elementos más básicos y personales de su concepto de la propia existencia.

Otro tipo de desintegración entre el personaje y su "mismidad" ocurre con la determinación de la presencia física por una sola manifestación de la misma. Por ejemplo: un grito, una canción, etc., señalan la presencia de un ser humano sin que se presente en su totalidad. Examinemos el primer párrafo del cuento "El hombre":

Los pies del hombre se hundieron en la arena, dejando una huella sin forma, como si fuera la pezuña de algún animal. Treparon sobre las piedras, engarruñándose al sentir la inclinación de la subida, Iuego caminaron hacia arriba, buscando el horizonte. 5

El hombre, como entidad física, no se presenta hasta el final del cuento. Pero su presencia, sus acciones y hasta sus actitudes se revelan por los pies y las huellas que ha dejado en la tierra. Cuando al fin lo vemos en su totalidad, el hecho es casi anticlimático. Ya lo conocemos. Ya sabemos cómo es, qué ha hecho, y cómo ha reaccionado frente a sus acciones. Su presencia es más patente que la del personaje que lo persigue (a quien conocemos desde el principio en su totalidad física). Lo hemos conocido por sus pies: el espacio entre éstos, los lugares en los cuales se para, etc. - toda manifestación de su pasar nos dice algo de su crimen y de su personalidad.

Es importante señalar que en el mundo de Rulfo todos estos tipos de desintegración parecen naturales, hasta esperados. No son meras manifestaciones de técnica literaria, sin otra función. Forman parte integra del medioambiente en que lo incongruente es lo congruente.

5 Ibid, p. 37. 


\section{INTENSIFICACIÓN}

$\mathrm{La}$ intensificación se relaciona ante todo con el estilo. Básicamente el estilo de Rulfo es directo, por lo general en forma de monólogo dirigido al lector o de diálogo entre dos o tres personajes. Casi siempre se presenta en primera persona. Esto, más la notable ausencia de narración, lo pone todo en un plano ultra-personal e íntimo. Hay una mezcles. de tiempos, o más bien, una interrelación de tiempos que intensifica y dai nueva importancia a los hechos específicos que ocurren en cualquier momento dado.

La repetición figura en primer plano como parte del estilo de nues: tro autor. Por ejemplo, en el cuento "Macario", en el cual habla un niño retardado, hay una serie de frases que empiezan todas con "Y".

Y uno da de topes contra el suelo; primero despacito, después más recio y aquello suena como un tambor. $\mathrm{Y}$ entonces uno estál en la iglesia, amarrado a la madrina, oyendo afuera el tum tum del tambor. Y mi madrina dice que si en mi cuarto hay chinches $y$ alacranes es porque me voy $a$ ir a arder en el infierno...6

La técnica muestra aquí las dos fuerzas que operan en la vida del niño: el deseo de hacerse coherente y ser entendido, y su defecto mental que no se lo permite. La repetición también tiene niveles de progresión que aumentan de intensidad con cada uso de la palabra elegida o sus equivalentes. Veamos, por ejemplo, el empleo de la palabra "muerto" y sus variantes en el pasaje siguiente:

-Ese que está alli tirado parece estar muerto o algo por cl estilo. -No, nada más ha de estar dormido...

Yo fui y le di una patada en las costillas para que despertara; pero el hombre siguió igual de tirante.

-Está bien muerto - les volví a decir.

-No, no te creas, nomás está tantito atarantado porque Odilón le dio con un leño en la cabeza...

Ya por último le di una última patada al muertito ...7

La palabra "muerto" aparece por primera vez en yuxtaposición con la frase "o algo por el estilo". Esto indica una actitud ligera, todavía insegura, sin emoción, ni siquiera espanto, con que se mira la posibilidad de la muerte. Después aparece en forma combinada, más decisiva,

6 Ibid, "Macario", p. 12.

7 Ibid, "La cuesta de las Comadres", p. 25. 
"bien muerto", definitivamente enfática. Por último, aparece en el diminutivo, con un tono casi íntimo, hacia un "fait accompli" irremediable.r

Es interesante notar que el progreso técnico está bien claro, perof no produce emoción. Al contrario, es una intensificación de la muerte en sí y no de las reacciones de los personajes ante el hecho. El énfasis recae en el suceso y no en los que lo observan.

Esta misma cita nos lleva a examinar otra técnica de intensificación. Es la que en inglés suele llamarse "understatement". En Rulfo apareca en la actitud ultra-pasiva que asume ante los hechos violentos; hechos que deben ir o que suelen ir acompañados de cierta emoción o, por lo menos, de una reacción adecuada al impacto que se esperaría de tal suceso. La técnica de contar tales sucesos en un tono tan "matter-of-fact", tan simple y pasivo, da a los hechos una intensidad tremenda. Es una técnica por la cual el autor hace hincapié en el acto mismo, más bien que en la narración de éste.

Ese "approach" nos dice mucho sobre la perspectiva de Juan Rulfo; no sólo su perspectiva literaria, sino también su actitud hacia el hombre individual. El hombre no es más que otro elemento del mundo. Na tiene más importancia ni más significado que los demás componentes de la realidad. Es, como hemos visto, un mundo grotesco que se hace real por ser presentado en una forma tan extraordinaria, tan fuera de la realidad concreta. Este efecto se logra mediante una actitud ultrarealista, en la que la descripción de una muerte o la de un árbol son iguales en su falta de sentimiento. El árbol y la muerte participan; ambos, de una sola realidad; de modo que ni el uno ni la otra tiene más importancia dentro del esquema general de esa realidad. El mundo existe por sí mismo, como entidad objetiva, y la presencia o falta de un árbol más o un hombre más no lo altera ni lo afecta profundamente.

Los tres procesos que hemos mencionado en estas notas son lor que determinan, a nuestro parecer, la mayor parte del estilo de Juar Rulfo. Cada uno tiene su propia función dentro de la obra y cada una produce un efecto distinto. No obstante, hay que notar que es la com-1 binación e interacción de los tres lo que produce el efecto desconcertante de la obra. El mundo de Juan Rulfo determina y está determinado por estos tres elementos, que llegan a convertir realidades de por sí increíbles en realidades patentes y sorprendentes.

DIANE E, HILL

University of Pittsburgh 